\title{
USING ON-LINE VIDEO CLIPS TO ENHANCE SELF-EFFICACY TOWARD DEALING WITH DIFFICULT SITUATIONS AMONG NURSING STUDENTS
}

\begin{abstract}
The aim of the study was twofold. The first aim was to develop on-line video clip material that showed examples of nurses dealing with potentially difficult and delicate patient groups. The second aim was to evaluate the effectiveness of video clip materials for enhancing nursing student's self-efficacy to effectively communicate with the type of patients described above. The production of contextually relevant video clip material involved the identification of relevant material based on real experiences, writing appropriate scripts, recruiting actors, recording the performances and producing them in a form that could be accessed on-line. Self-report questionnaires were used to assess the effectiveness of video clip material. Level 1 $(n=145)$ nursing students completed a self-efficacy measure that assessed confidence to deal with situations such as breaking news of death, working with children, people with disability and aggressive behaviour at the start and the end of the module. Results indicated that student's self-efficacy increased significantly over the course of the module. Differences between increases in self-efficacy attributed to watching videos or attending lectures were marginal. Findings suggest that using video clips that show students effectively coping with adverse situations provide an effective teaching approach for enhancing self-efficacy. Future research is needed to test the extent to which self-efficacy measures relate with nursing performance.
\end{abstract}

Keywords: Self-efficacy, information technology, nursing performance. 


\section{INTRODUCTION}

A key issue in training nursing students is developing patient care skills. Nursing students need to learn how to make clinical judgements of patients' needs and be able to communicate this knowledge in an appropriate way. Neary (1997) argued that students are not able to effectively care for patients simply by having knowledge and skills; they must learn to apply those skills in real-life situations. These skills tend to be developed through a combination of didactic lectures supplemented by seminars and workshops (Laurillard 1993). It should be noted that students typically express concern on the effectiveness of classroombased preparation for practical placements. One strategy to complement traditional teaching methods is through simulating situations that occur in hospitals. Educators have debated whether practical skills to deal with patients should be taught only in the real world situations, although this is potentially a risky approach as poor performance can have damaging effects on the welfare of the patients and / or the well being of students (Neary 1997). It is argued that students could learn practical skills through simulating real world situations in the classroom, an approach that allows students to make mistakes in a comparatively safe environment. The strength of the debate and the importance of the issue, emphasises the need for research to explore teaching methods to enhance student's ability to deal with adverse patient care issues.

Recent research has used simulation as part of patient health care with varying degrees of success (Alinier et al 2004; Cioffi 2001; Cleave-Hogg \& Morgan 2002; Treadwell \& Grobler 2001). Indeed, Chau et al (2001) conducted an experiment that involved 83 students completing pre and post tests that assessed critical thinking and knowledge. They concluded that improved performance was associated with watching videotaped vignettes. Follow-up interview results alluded to some of the possible mechanisms that could underpin this effect. 
Students reported perceived heightened focus on the skills needed for success. This explanation suggests that increased performance could be indexed to improved motivation.

A relevant theoretical framework for building students skills, motivation and confidence to deal with adverse patient care issues is self-efficacy (Bandura 1997). Selfefficacy is defined as the levels of confidence individuals have in their ability to execute courses of action or attain specific performance outcomes (Bandura 1997). Self-efficacy is the confidence to deal with the demands of a specific situation and is conceptually different to self-esteem, which is a more general estimate of self-worth across all situations (Bandura 1997). Self-efficacy is linked with successful performance in a range of different domains including academic tasks (Multon et al 1991; Schunk 1995; Pajares 1996), work (Stajkovic \& Luthans 1998) and sport (Moritz et al 2000). Thus, given sufficient skills, educational methods that enhance self-efficacy could enhance the confidence of trainee nurses to communicate with difficult and delicate patient groups.

An attractive aspect of self-efficacy theory for practitioners is the notion that it is malleable and can be enhanced through training. Self-efficacy is influenced by processing information from four main sources (Bandura 1997). The first source of self-efficacy is personal performance accomplishments, whereby success raises self-efficacy and failures lowers self-efficacy. The second source of self-efficacy is vicarious experiences, whereby watching successful performances can raise self-efficacy and watching failures can lower selfefficacy. A more powerful effect is observed when there is similarity between the actor and observer, thereby installing the attitude 'if he can do it, so can I' (Bandura 1986). The third source of self-efficacy is verbal persuasion where encouragement can increase self-efficacy. For example, if the lecturer convinces a student of his/her competence on a task, the student's self-efficacy should improve. The fourth source of self-efficacy is the control of physiological states such as those associated with emotional arousal. Controlling emotional arousal is 
particularly important when individuals attempt to complete tasks that are personally important as these tasks illicit intense emotional states.

Although self-efficacy theory offers theoretical suggestions for enhancing selfefficacy, implementing intervention strategies is not so straightforward. Educational providers typically teach large numbers of students and thus providing on-going and individual feedback can be difficult. An emergent issue within Higher Education is the use of Technology supported learning. If appropriate video clips were made, Technology Supported Learning would provide students with an opportunity to view on-line role play situations on multiple occasions. Further, Technology Supported Learning has been found to benefit students who struggle to attend face to face lectures and those who are visual, rather than auditory learners. Importantly from a delivery perspective, Technology Supported Learning provides a semi-permanent resource and so students can re-visit the clips, which has the potential to develop a greater understanding of the difficulties of the task. Studies have shown that the use of technology has helped students adopt deeper approaches and learn because they feel less inhibited than if they had to participate in role play in front of a large class (Olaniran et al 1996; Freeman \& Capper 1997).

Collectively, given the need to enhance the self-efficacy of nurses to cope with a range of difficult and delicate situations, the purpose of the present study was twofold; 1) to develop video clip material for use on an e-learning framework that simulates contextually relevant examples, and 2) conduct a preliminary evaluation of the effectiveness of video clip materials on enhancing student's self-efficacy.

\section{$\underline{\text { OVERVIEW }}$}

The research was conducted in a university in which diversity and widening participation are key issues. Nursing modules are typically taught in large class sizes and problems associated with large groups from diverse backgrounds are particularly relevant. For 
example, English is not the first language of many students. The module used in the research project, attempted to use a teacher-centred approach to learning in which the teacher is responsible for planning and delivering lectures to the group as a whole. A module runs for 15-weeks and the majority of sessions are lecturers to the whole cohort. The sessions allocated to the topic of dealing with adverse situations were delivered as a lecture with a discussion around practical examples given from the lecturers' own personal experiences.

The research formed part of a strategy designed to enhance teaching and learning. The research evaluated a development of a teaching method designed to enhance the quality of the student-experience. The researchers sought to maintain ecological validity when assessing the effectiveness of the intervention. The design of the module precluded separating students into a control group and experimental group. We deemed it ethically appropriate that all students should be equally exposed to the desirable treatment and therefore evaluated with the effectiveness of the use of watching video clips using a pre-post test design. It is acknowledged that a limitation that it is difficult to attribute significant changes in post-test self-efficacy scores to the watching video clips using this design. In an attempt to counter this limitation, we asked students to rate the extent to which watching the videos was associated with self-efficacy estimates.

\section{$\underline{\text { METHODS }}$}

\section{$\underline{\text { Participants }}$}

Volunteer Level 1 nursing students $(\mathrm{N}=145$; Age range 18-45 years) participated in the research. Students completed an informed consent form in which they agreed for their data to be used in the project. When evaluating teaching methods it is rare to obtain ethical clearance before commencement of the project and therefore the project was not presented to the ethics board. Students who wished not to participate were allowed to access the materials 
developed for the research. Students in the project were not treated in any way differently to students in the cohort who chose not to participate.

Participants were based on one of the hospital sites attached to the University. There was a combination of both male and female students from a variety of backgrounds and cultures. Participants described previous experiences considered helpful toward dealing with difficult situations that could be faced as a nurse. Fifty-three participants indicated that they had no experience of situations that could be relevant to nursing, 50 students had some experience relevant to nursing, and 41 students reported having some experience of nursing. Development of video clip support material

Video clips were developed as a teaching aid for a unit for nursing students in Level 1 in the first term of a three-year full-time programme. The video clips were designed to enhance and compliment the content of the module 'Communication and Customer Care'. Students from a previous cohort were consulted to identify relevant situations that should be used as the basis of video clip material. Students revealed that dealing with bereavement and aggression headed the list of difficult situations.

A key-part of how vicarious experiences enhance self-efficacy is through providing a clear understanding of the difficulties of the task. The decision was made to make video clips that showed someone dealing with the task using appropriate behaviour and contrast this with someone dealing with the task using inappropriate behaviour. By showing a range of different ways in which similar situations were tackled, it was hoped that the students would develop a clearer understanding of task difficulties. During the development of the video clips, it was emphasised that both successful and unsuccessful behaviours to deal with difficult patients were based on real-life situations, and the likely fact is that many students will make mistakes during the course of their career. 
After the scripts were written, actors were recruited from colleagues from the School of Health, members of staff at the local hospice, and members of a Learning Disability Advocacy group. The production team included a video producer and editor, a freelance sound engineer, two professional make up artists from The Royal Shakespeare Company and six students from the Media Department at the University. The actors granted permission for the video clips to be used for publication purposes. The audiotape information on the programme was recorded and transferred onto the computer by the course technician.

Eighteen high quality video clips were produced to use within the module. The video clips are intentionally short - lasting between 2 to 3 minutes (the length of the film was reduced mainly to keep computer file sizes to be manageable for software to be used). This introduces the student to a 'flavour' of realistic situations and how to cope. Mackenzie and Staley (2000) proposed that when students see the relevance and can make the connections between theory and 'the real world', the level of interest improves dramatically.

All video clips were transferred to the University on-line learning framework by the course technician so they could be viewed by students using Windows Media Player. To ensure that the clips could be viewable at all locations the clips were re-compressed by the IT services in both 100k and 56k sizes, although it is acknowledged that this reduced the quality of the video clips, it made them more accessible.

A workbook was produced explaining to the students how to log onto the appropriate site and access the video clips. Students could revisit the clips in their study time to allow them to continually review the content and deepen their learning and understanding of how to cope when faced with similar situations on their placements. 
$\underline{\text { Measures of self-efficacy }}$

\section{$\underline{1 .}$ Baseline measure of self-efficacy}

Bandura (1997) proposed that researchers should develop concordance between selfefficacy and the behaviours needed to deliver performance. As each situation will have components that are unique, it is unlikely that a common self-efficacy scale would suffice. This raises a potential issue regarding the development of factorally valid and reliable selfefficacy scales. It is arguably more important to develop a scale that has content validity in that it assesses the key factors in the situation where the research is conducted. The inability to develop a valid scale inherently means that the generalisability of findings is limited to the sample under investigation. However, and consistently with self-efficacy theory, it is possibly better to demonstrate the utility of a scale through cross-validation. Therefore, in the present study, self-efficacy measures were targeted towards situations / set of circumstances related to course content, and particularly, video clip content. A six-item self-efficacy toward nursing scale was developed. We argue that these are the important issues in the present study and encourage other researchers to explore the factors that underpin performance when developing a self-efficacy scale. In the present study, participants were asked 'How confident are you of successfully dealing' with:

1. Having to break bad news to a relative of an unexpected death;

2. Having to break bad news to a relative of an expected death;

3. A patient that ask if he/she is going to die;

4. An aggressive patient;

5. Having to communicate with a person who has a learning disability;

6. Having to communicate with a child. 
Participants rated self-efficacy on a 5-point scale, where $1=$ no at all confident and 5 $=$ very confident. The questionnaire is contained in Appendix 1 and can be used freely by other researchers.

\section{Post-module assessment of self-efficacy}

Post-module self-efficacy was assessed using the same scale used to assess premodule self-efficacy. In an attempt to identify the extent to which participants felt traditional lectures and watching the video clips contributed, a 12-item questionnaire was developed. Participants rated the extent to which watching video clips contributed to increased my confidence toward the same six situations on a 5-point scale ranging from 'not at all' (1) to 'very effective' (5). Participants rated the extent to which the actions of the lecturers in the module increased their self-efficacy towards the same six situations on a similar five-point scale. This questionnaire is contained in Appendix 2 and also free to use by other researchers. $\underline{\text { Procedure }}$

Students were asked to participate in a research project at the start of the lecture. Students were informed of the nature and purpose of the study and it was made explicit that the research was designed to critically evaluate teaching methods to improve performance when they became trainee nurses. The importance of making honest and accurate estimates of confidence was stressed. Students were informed that there were no right or wrong answers, confidentiality was assured, and no incentives were offered for participation in the research. The video clips were shown to the April 2002 intake of students across all hospital sites of the School of Health.

Multivariate analysis of variance (MANOVA) was used to investigate changes in selfefficacy over time and also to compare whether video clips had a more powerful effect on self-efficacy than attending lectures. 


\section{$\underline{\text { RESULTS }}$}

Descriptive statistics for self-efficacy scores over time are contained in Table 1. MANOVA to compare differences in self-efficacy over time indicated a significant main effect (Wilks' Lambda $6,277=.96, P<.05$, Partial Eta ${ }^{2}=.04$, see Table $\left.z \underline{1}\right)$. There was no main effect for gender (Wilks' Lambda $6,277=.99, P>.05$, Partial Eta $^{2}=.01$ ) and no interaction effect (Wilks' Lambda $6,277=.99, P>.05$, Partial Eta ${ }^{2}=.008$ ). Univariate results show that self-efficacy toward having to break bad news to a relative of an unexpected death and self-efficacy toward having to break bad news to a relative of an expected death increased significantly over time.

With reference to the second questionnaire that evaluated perceived effectiveness of the use of video clips within the course, a comparison of the influence of the relative contribution of lecturers and video clips on self-efficacy showed no significant effect. It should be acknowledged that the result was borderline (Wilks' Lambda ${ }_{6,136}=.91, P=.05$, Partial Eta ${ }^{2}=.08$, see Table $3 \underline{2}$ ).

\section{$\underline{\text { DISCUSSION }}$}

The present study attempted to enhance self-efficacy to deal with difficult patient care situations. In addition to the traditional lecture, seminar, and tutorial method of teaching, video clips that showed students how to cope successfully and unsuccessfully with a range of difficult situations were developed. The present study builds upon a growing literature that suggests that students can learn by watching appropriate video taped sessions (Alinier et al., 2004; Cioffi, 2001; Chau et al., 2001; Cleave-Hogg, \& Morgan, 2002; Treadwell \& Grobler, 2001). Self-efficacy was used as the variable to assess the effectiveness of courses/modules designed to raise performance in specific skills as previous research has verified that it is predictive of performance (Bandura 1997; Stajkovic \& Luthans 1998).

As Table 1 shows, self-efficacy expectations toward having to break bad news to a 
relative of an expected death and unexpected death increased significantly. Table 2 indicates that there was no significant difference in the efficacy enhancing effects of information given by lecturers or through students accessing the information on-line through watching video clips. We suggest that the combination of theoretical information delivered in lectures and viewing examples of patient care skills on video provided students with a much clearer understanding of task difficulties than what could have been achieved through a traditional lecture based only approach. It is also important to recognise that findings from the present study suggest that on-line delivery should compliment student learning rather than replace it.

Results highlight the potential for lecturers to make use of technological advances. Information technology supported learning could be used to develop a flexible curriculum that suits a wide range of student ability in pre-registration nursing programmes (UKCC, 1999). In the present study, the development of the video clips facilitates an additional method of delivery, and importantly, allows students to observe simulated real life scenarios repeatedly. The benefit being that the students may feel more confident in coping with these situations when they encounter them on their clinical placements. Indeed learning theory suggests that such contextualisation of information would aid meaningful learning experiences (Knowles 1990; Kolb 1984).

Although practical recommendations that come out from this study tend to rely on technology, this is not the only possibility. Self-efficacy theory proposes that people can learn by watching others when the similarity between actor and observer is close (Bandura 1997). One approach to do this is to integrate levels of students across the programme. Typically, students are taught in Level 1, Level 2 etc with students across level not mixing. Integration could occur if Level 2 students, who had been out on a nursing placement were asked to describe these experiences to Level 1 students, who were being taught the necessary skills before their first placement. A key feature of developing professionalism is through self- 
reflection of performance. By asking Level 2 students to reflect and share their experiences with Level 1 students, this would make the process of self-reflection explicit to students, especially if the work formed part of an assessment for Level 2 students. Level 1 students would have models of varying degrees of success on which to judge the relationship between the difficulties of the task against their perceived ability. It is argued that Level 2 students who recently experienced the situation, would provide the most appropriate model of performance. These students are likely to be similar to Level 1 students in terms of age and previous experience (Bandura, 1997).

Future research should investigate the stability of increased self-efficacy following completion of the module. Although findings of the present study indicated enhanced selfefficacy, the stability of such improvements is unknown, and thus it is not known whether this confidence has fragile qualities that break when the student addresses such issues on placement. Efficacy enhanced through witnessing the experience of another person or through persuasion is proposed to be less powerful than performance accomplishments.

\section{CONCLUSIONS}

In conclusion, the project successfully developed video clips that simulate real life scenarios likely to be encountered by nurses during their training and then throughout their career. Results shows that the video clips provide effective support material and successfully increase self-efficacy towards dealing with these situations. Video material provides students the opportunity to re-visit the clips as many times as they wish outside of the classroom environment. Future research should investigate relationships between self-efficacy and nursing performance. 


\section{ACKNOWLEDGEMENTS}

The authors would like to thank the following for their help with developing suitable video clips: Jane Rowley, Ally Fellows, Andrew Bagnall, Maureen Moss, David Jurissic, Alison Littleford, John Adams, Jane Jones, Rodge Byrne, Lesley Hollingshead, Christine Hollingshead, Eileen Brewer, Michael Lee, Meegan Price, J.C. Carthy, Vicki Jackson, Rita Bayley, Alex Johnson, Rose Clark, Yvette Foster, Navin Foolchand, Gary McConville, Charlotte Griffiths, Rachel Seal, John Wiggins, Steve Jeffs, Jeremy Brown, Emma Causton, Georgina Field, Scott Whitten, Cherie Newton, Andrew Reilly, James Stringer, Simon Roberts, Alan Smith, Bob Saunders, Gilly Jones, Colin Dalziel, Pam Collins, Louise Rennison, Trudi Millard, Natalie Hawkins, Lynne Westwood, Kay Biscomb, Wendy Moran, and Millie Smith.

The Project was funded by a Centre for Learning and Teaching Grant by the University of Wolverhampton. 


\section{REFERENCES}

Alinier G., Hunt W. B., Gordon R., 2004. Determining the value of simulation in nurse education: Study design \& initial results. Nurse Education in Practice 4(3), 200-207

Bandura, A., 1986. Social foundation of thought and action: A Social Cognitive Therapy. Prentice-Hall, Englewood Cliffs, NJ.

Bandura, A., 1997. Self-efficacy: The exercise of control. New York, WH Freeman.

Chau, J.P.C., Chang A.M., Lee, I.F.K., I, W.Y., Lee, D.T.F., Wootton, Y., 2001 Journal of advanced nursing, 36 (1), 112-119

Cioffi, J., 2001. Clinical simulations: development and validation. Nurse Education Today $21,477-486$

Cleave-Hogg, D., Morgan, P., 2002. Experiential learning in an anaesthesia simulation centre: analysis of students' comments. Medical Teacher 24 (1), 23-26

Freeman, M., Capper, J., 2000. Obstacles and opportunities for technology innovation in business teaching and learning. International Journal of Management Education, 1 (1), 37 47

Knowles, M., 1990. The adult learner: a neglected species. $4^{\text {th }}$ edition Gulf Publishing, Houston, Texas.

Kolb, D. A., 1984. Experiential learning: experience as a source of learning and development. Prentice Hall, Englewood Cliffs, NJ.

Laurillard, D., 1993. Rethinking university education: A framework for the effective use of educational technology. Routledge: London.

Mackenzie, N., Staley, A., 2000. Online professional development for academic staff: Putting the curriculum first. Innovations in Education and Teaching International, 38 (1), 4253 
Moritz, S. E., Feltz, D. L., Fahrbach, K. R., Mack, D. E., 2000. The relation of selfefficacy measures to sport performance: A meta-analytic review. Research Quarterly for Exercise and Sport, 71 (3), 280-294

Multon, K. D., Brown, S. D., Lent, R. W., 1991. Relation of self-efficacy beliefs to academic outcomes: A meta-analytical investigation. Journal of Counselling Psychology, 38 (1), 30-38

Neary, M., 1997. Project 2000 students' survival kit: a return to the practical room nursing skills laboratory. Nurse Education Today, 17 (1), 46-52

Olaniran, B., Savage, G., Sorenson, R., 1996. Experimental and experiential approaches to teaching face to face and computer mediated group discussion. Communication Education, 45 (3), 244-259

Pajares, F., 1996. Self-efficacy beliefs in academic settings. Review of Educational Research, 66 (4), 543-578

Peach, L., 1999. Fitness for practice: UKCC Commission for Nursing and Midwifery Education. London: United Kingdom Central Council

Schunk, D. H., 1995 Self-efficacy and education and instruction. In J. E. Maddux Ed, Self-efficacy, adaptation, and adjustment: Theory, research, and application, pp. 281-303 New York: Plenum Press.

Stajkovic, A. D., Luthans, F., 1998. Self-efficacy and work-related performance: A meta-analysis. Psychological Bulletin, 124 (2), 240-261

Treadwell, I., Grobler, S., 2001. Students' perceptions on skills training in simulation. Medical Teacher 23 (5), 476-482 
Table 1

Self-efficacy toward dealing with difficult situations in nursing over time before and after use of video clips

\begin{tabular}{|c|c|c|c|c|c|c|}
\hline & \multicolumn{2}{|c|}{ Start of the module } & \multicolumn{2}{|c|}{ End of the module } & \multirow[b]{2}{*}{$\begin{array}{l}F \\
\text { ratio }\end{array}$} & \multirow[b]{2}{*}{$\begin{array}{l}\text { Partial } \\
E_{t a}^{2}\end{array}$} \\
\hline & Mean & $\begin{array}{l}\text { Standard } \\
\text { Deviation }\end{array}$ & Mean & $\begin{array}{l}\text { Standard } \\
\text { Deviation }\end{array}$ & & \\
\hline $\begin{array}{l}\text { Having to break bad news to a } \\
\text { relative of an unexpected death }\end{array}$ & 2.12 & 0.98 & 2.86 & 0.84 & $10.70 *$ & .037 \\
\hline $\begin{array}{l}\text { Having to break bad news to a } \\
\text { relative of an expected death }\end{array}$ & 2.59 & 1.08 & 3.31 & 0.84 & $8.12 *$ & .028 \\
\hline $\begin{array}{l}\text { A patient that asks if he/she is } \\
\text { going to die }\end{array}$ & 2.49 & 1.27 & 3.08 & 0.87 & 3.62 & .013 \\
\hline An aggressive patient (s) & 3.04 & 1.01 & 3.33 & 0.89 & 0.30 & .001 \\
\hline $\begin{array}{l}\text { Having to communicate with a } \\
\text { person who a learning disability }\end{array}$ & 3.38 & 1.00 & 3.73 & 0.84 & 0.32 & .001 \\
\hline $\begin{array}{l}\text { Having to communicate with a } \\
\text { child }\end{array}$ & 4.08 & 0.94 & 4.11 & 0.93 & 0.37 & .001 \\
\hline
\end{tabular}

$1=$ Not effective at all, $5=$ Very effective

$* \mathrm{P}<.01$ 
Table 2

Comparison of the influence of information gleaned from watching video clips and attending lectures on self-efficacy

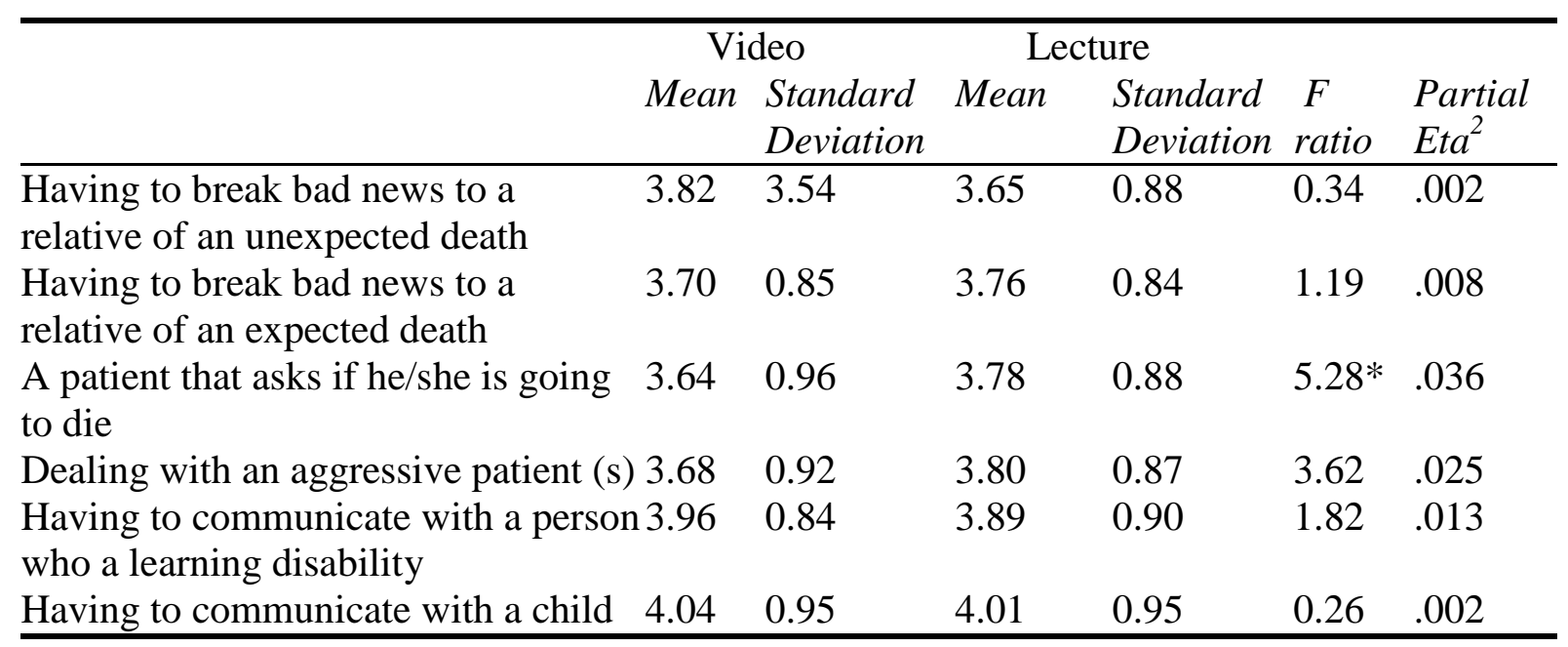

$1=$ Not effective at all, $5=$ Very effective

$* \mathrm{P}<.05$ 


\section{Appendix 1}

\section{Dealing with adverse situations in nursing Questionnaire}

Name Gender: _ $\mathrm{M} / \mathrm{F}$

On a scale from $1-5$, where $1=$ no at all confident and $5=$ very confident, estimate how confident are you successfully dealing with:

\begin{tabular}{|l|l|l|l|l|c|}
\hline $\begin{array}{l}\text { How confident are you of successfully } \\
\text { dealing: }\end{array}$ & $\begin{array}{l}\text { Not } \\
\text { at all }\end{array}$ & & & $\begin{array}{c}\text { Very } \\
\text { confident }\end{array}$ \\
\hline $\begin{array}{l}\text { Having to break bad news to a relative of an } \\
\text { unexpected death }\end{array}$ & 1 & 2 & 3 & 4 & 5 \\
\hline $\begin{array}{l}\text { Having to break bad news to a relative of an } \\
\text { expected death }\end{array}$ & 1 & 2 & 3 & 4 & 5 \\
\hline$\circ \quad$ A patient that asks if he/she is going to die & 1 & 2 & 3 & 4 & 5 \\
\hline$\circ \quad$ An aggressive patient (s) & 1 & 2 & 3 & 4 & 5 \\
\hline$\circ \quad \begin{array}{l}\text { Having to communicate with a person who } \\
\text { a learning disability }\end{array}$ & 1 & 2 & 3 & 4 & 5 \\
\hline$\circ \quad$ Having to communicate with a child & 1 & 2 & 3 & 4 & 5 \\
\hline
\end{tabular}

Previous experience: Please describe any relevant previous experience that you think would help you deal with difficult situations that you could face as a nurse: 
Appendix 2

Name

Dealing with adverse situations in nursing Post module Questionnaire Gender: M / F

\section{Section 1: About your confidence to deal with difficult situations}

On a scale from $1-5$, where $1=$ no at all confident and $5=$ very confident, estimate how confident are you successfully dealing with:

\begin{tabular}{|c|c|c|c|c|c|}
\hline $\begin{array}{l}\text { How confident are you in your ability to } \\
\text { successfully dealing with: }\end{array}$ & $\begin{array}{l}\text { Not } \\
\text { at all }\end{array}$ & & & & $\begin{array}{c}\text { Very } \\
\text { confident }\end{array}$ \\
\hline $\begin{array}{ll}\text { Having to break bad news to a relative of an } \\
\text { unexpected death }\end{array}$ & 1 & 2 & 3 & 4 & 5 \\
\hline $\begin{array}{l}\text { Having to break bad news to a relative of an } \\
\text { expected death }\end{array}$ & 1 & 2 & 3 & 4 & 5 \\
\hline$\circ \quad$ A patient that asks if he/she is going to die & 1 & 2 & 3 & 4 & 5 \\
\hline $\begin{array}{ll} & \text { An aggressive patient }(\mathrm{s})\end{array}$ & 1 & 2 & 3 & 4 & 5 \\
\hline $\begin{array}{ll}\circ & \text { Having to communicate with a person who a } \\
\text { learning disability }\end{array}$ & 1 & 2 & 3 & 4 & 5 \\
\hline Having to communicate with a child & 1 & 2 & 3 & 4 & 5 \\
\hline
\end{tabular}

Section 2: About your watching video clips on WOLF.

On a scale from $1-5$, where $1=$ not effective at all and $5=$ very effective, rate the extent to which watching the video clips on WOLF have contributed towards your confidence to deal with:

\begin{tabular}{|c|c|c|c|c|c|}
\hline $\begin{array}{l}\text { Watching video clips on WOLF has } \\
\text { increased my confidence toward: }\end{array}$ & $\begin{array}{l}\text { Not } \\
\text { at all }\end{array}$ & & & & $\begin{array}{c}\text { Very } \\
\text { effective }\end{array}$ \\
\hline $\begin{array}{ll}\text { O Having to break bad news to a relative of an } \\
\text { unexpected death }\end{array}$ & 1 & 2 & 3 & 4 & 5 \\
\hline $\begin{array}{ll}\text { O Having to break bad news to a relative of an } \\
\text { expected death }\end{array}$ & 1 & 2 & 3 & 4 & 5 \\
\hline$\circ \quad$ A patient that asks if he/she is going to die & 1 & 2 & 3 & 4 & 5 \\
\hline O An aggressive patient (s) & 1 & 2 & 3 & 4 & 5 \\
\hline $\begin{array}{ll}\circ & \text { Having to communicate with a person who a } \\
\text { learning disability }\end{array}$ & 1 & 2 & 3 & 4 & 5 \\
\hline Having to communicate with a child & 1 & 2 & 3 & 4 & 5 \\
\hline
\end{tabular}

Section 3: About how much confidence your lecturers have given you

On a scale from $1-5$, where $1=$ not effective at all and $5=$ very effective, rate the extent to which lecturers on the module have contributed towards your confidence to deal with:

\begin{tabular}{|c|c|c|c|c|c|}
\hline $\begin{array}{l}\text { Lecturers in the module have increased my } \\
\text { confidence toward: }\end{array}$ & $\begin{array}{l}\text { Not } \\
\text { at all }\end{array}$ & & & & $\begin{array}{c}\text { Very } \\
\text { effective }\end{array}$ \\
\hline $\begin{array}{l}\text { Having to break bad news to a relative of an } \\
\text { unexpected death }\end{array}$ & 1 & 2 & 3 & 4 & 5 \\
\hline $\begin{array}{l}\text { Having to break bad news to a relative of an } \\
\text { expected death }\end{array}$ & 1 & 2 & 3 & 4 & 5 \\
\hline$\circ$ A patient that asks if he/she is going to die & 1 & 2 & 3 & 4 & 5 \\
\hline An aggressive patient (s) & 1 & 2 & 3 & 4 & 5 \\
\hline $\begin{array}{ll}\text { Having to communicate with a person who a } \\
\text { learning disability }\end{array}$ & 1 & 2 & 3 & 4 & 5 \\
\hline o $\quad$ Having to communicate with a child & 1 & 2 & 3 & 4 & 5 \\
\hline
\end{tabular}

